\title{
Judo performance: kinanthropometric importance for technical tactical and biomechanics
}

\section{Análise de performance no judô: considerações cineantropométricas e biomecânicas}

\author{
Ciro José Brito \\ (D) https://orcid.org/0000-0002-9678-1977 \\ Esteban Aedo-Muñoz ${ }^{1,2}$ \\ (D) https://orcid.org/0000-0003-1544-2824 \\ Bianca Miarka ${ }^{1,3}$ \\ (D) https://orcid.org/0000-0002-7513-7605
}

\begin{abstract}
In such a competitive combat sport as judo, it is important that the training is carefully planned so that the athlete can stand out in the international competition. In this context, it is important that the trainer and evaluator are accurate regarding the measures taken of the athlete. Such measures, when correctly performed, can prepare the trainer with tools that allow prescribing contextualized training. The present point of view will show how kinanthropometric variables can be considered by coaches and evaluators when performing technical-tactical and biomechanical analysis in judo athletes. There are differences between sex and weight divisions as to the actions that are prevalent in each one of the categories. Lighter divisions performances must have specific training regarding approach and gripping. Attention should be paid to anticipation in athletes of the light and middle divisions. The rating of force development is the most important biomechanical measure.
\end{abstract}

Key words: Martial arts; Data analysis; Athletic performance; Body weights and measures.

Resumo - Em um esporte de combate competitivo como o judô, é essencial que o treinamento seja cuidadosamente planejado para o atleta se destacar na competição internacional. Nesse contexto, é imprescindivel que o técnico e o analista sejam precisos quanto às analises realizadas no atleta. Tais mensuraçôes, quando realizadas de forma correta, podem preparar o treinador com ferramentas que permitem prescrever treinamento contextualizados. O presente ponto de vista mostrará como as variáveis cineantropométricas podem ser consideradas por treinadores e avaliadores na realização de análises técnico-táticas e biomecânicas em judocas. Existem diferenças entre as categorias de peso e sexos quanto às ações prevalentes em cada um dos grupos. A atuação da divisão mais leve deve ter treinamento específico quan to à aproximação e pegada. Atenção deve ser dada à antecipação em atletas das categorias de pesos leves e médias. A taxa do desenvolvimento da força parece ser uma das medidas biomecânicas mais importantes.

Palavras-chave: Artes marciais; Analise de dados; Desempenho atlético; Pesos e medidas corporais.
1 Federal University of Juiz de Fora. Department of Physical Education. Laboratory of Physiological and Motor Analysis in Health and Performance. Juiz de Fora, MG. Brazil

2 Universidad de Santiago de Chile. Physical Activity, Sport and Health Sciences Laboratory. Santiago. Chile

3 Federal University of Rio de Janeiro. School of Physical Education and Sport. Laboratory of Psychophysiology and Performance in Sports \& Combats. Rio de Janeiro, RJ. Brazil

Received: May 21, 2020 Accepted: October 25, 2020

How to cite this article Brito CJ, Aedo-Muñoz E, Miarka B. Judo performance: Kinanthropometric importance for technical tactical and biomechanics. Rev Bras Cineantropom Desempenho Hum 2020, 22:e76584. DOl: http://dx.doi.org/10.1590/19800037.2020v22e76584

Copyright: This work is licensed under a Creative Commons Attribution 4.0 International License. 


\section{INTRODUCTION}

Judo biomechanists and notational analysts are worried about the analysis and enhancement of performance ${ }^{1}$. Authors of recent studies made wide use of video analysis and technology with important implications for assessment and training ${ }^{2}$, trying to improve knowledge about motor actions and lever used during determinant attacks ${ }^{1}$. Recently, those involved in these two sub-disciplines of sport science have recognized some other commonalities, which suggest that the two should grow closer together, collaborate more and share theories and methods ${ }^{3}$. The issues that are common to both biomechanists and notational analysts include optimizing feedback to the performer and coach to improve performance. These common issues include the management of information complexity ${ }^{4}$, addressing the reliability and validity of their data, and exploitation of the approaches and methods of artificial intelligence. However, the association between performance analysis and anthropometric analysis seems to be scarce.

There are many kinanthropometric measures that can be used to predict the judo performance. We can separate them in: a) determine an athletic performance; b) select possible talents for the sport; and c) differentiate groups of athletes between weight division and sex. Therefore, the present point of view aimed to present how anthropometric measures can be used in technical-tactical and biomechanical analysis for success in competitive judo. Such knowledge can help coaches and physical evaluators to focus on the assessments and variables that can really determine performance in this combat sport.

\section{IMPORTANCE OF TECHNICAL-TACTICAL ANALYSIS FOR MODERN TRAINING AND COMPETITION}

Investigations conducted weight division comparisons to provide further insights in the relationship between key-morphological variables and performance analysis ${ }^{5}$. When expensive high technology (ex. dual energy X-ray absorptiometry) appears to be unavailable and impractical for most sport scientists, descriptive anthropometric characteristics offer a unique wealth of information that can be used to analyze the size, proportionality and body composition of the athlete.

Even today, it is common that athletes train at the same volume and intensity in judo decontextualized trainings. However, there are differences in technical-tactical actions between men and women in the seven weight divisions. In elite athletes, a higher difference was observed between tactical actions when men and women were analyzed in their respective weight divisions. The lightest categories are those which need more attention regarding the tactics for the grip domain. Furthermore, between men and women in the middleweight there is a higher difference in the time dedicated to approaching and grappling, in which men tend to devote more time to the approach ${ }^{6}$. These data show the need to plan (at least 
part of the training) in a specific way, so that athletes can develop precise preparation for the demands of their division.

Regarding performance analysis, the main transitions between judo combat factors presented higher prevalence of the following combinations: approach phase, gripping occurring before the lever and attacks, attack occurring earlier than the groundwork and pause phase ${ }^{2}$. Regarding the approach phase of judo, high frequencies could be used by athletes to engage in evasive gripping actions in order to control space and ultimately gain control of their opponent for subsequent attacks ${ }^{7}$. Figure 1 shows the schematic division to perform a judo combat analysis.

Studies about performance analysis in judo associated with Kinanthropometry characteristics could explain the connection between determinant combat phases and their technical-tactical analysis ${ }^{6,7}$. For instance, weight divisions demonstrated significant performance differences associated with physical differences, light and middle categories rapidly analyze their adversary and execute their anticipated gripping tactics, which has been recognized to be a key factor in technical efficacy ${ }^{2}$. However, a possible explanation for these differences is the fact that these groups had a higher number of anthropometric standardized athletes in absolute volume participating in judo tournaments than the extra lightweight and heavier categories. Therefore, lighters, half middle and middle judo athletes have to develop unpredictable or difficult forms of approach, avoiding typical approach positions and vulnerable positions.

Regarding the gripping phase, there is a range of primary and secondary factors influencing the development of judo expertise which need more research: gripping associated with high levels of power and produced torque appear to be one of the essential characteristics that determine success in competition ${ }^{7}$. Past study showed that middleweight athletes had higher gripping frequencies than other weight categories, particularly gripping more often with one hand targeting their opponent's back and sleeves ${ }^{5}$. Recent findings outline the relationship between balance control and the bilateral reactionary gripping task. It is possible that middleweight athletes use a varied number of grip combinations to avoid opponent attacks and to execute throwing techniques with the purpose of compromising their opponent's balance and causing them to fall to the ground ${ }^{2}$. In turn, future studies need to consider wingspan as one of the factors associated with defense for attacks, repositioning the control through a strength grip and counterattacking. On the other hand, heavier athletes used more defensive grip configurations (i.e. back and collars) associated with the absolute weight on the opponent's shoulders, aiming to control their dynamic posture, and at the same time avoiding opponent's possible attempts to displace their balance (center of gravity), approaches and arm lever or minimal length techniques 5 .

\section{BIOMECHANICAL AND KINANTHROPOMETRY ASPECTS FOR JUDO PERFORMANCE}

Technical-tactical, biomechanical and Kinanthropometry characteristics of 


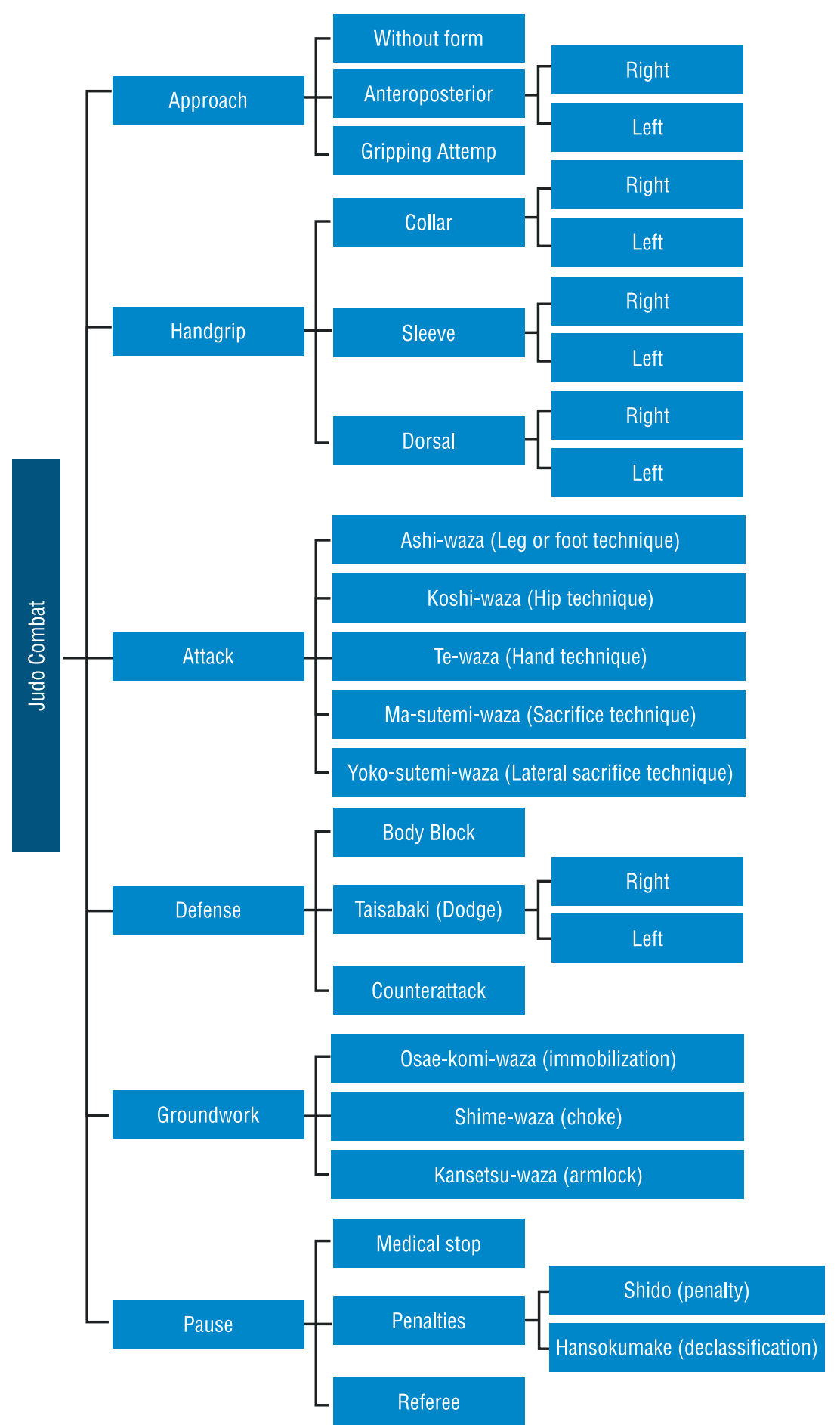

Figure 1. Division of technical-tactical actions to perform a judo combat analysis.

athletes influence performance and specific judo training. Currently, successful judo athletes demonstrated lower body fat percentage for both male and female, except for heavyweight athletes ${ }^{4}$. These variables are critical for coaches, who could benefit from relevant information to direct their decision in establishing a judo team roster, especially when the selection process is limited in time and weight divisions. Therefore, physical preparation should focus on improving muscular power and capacity in both upper and lower 
extremities of the body, considering technical-tactical analysis associated with biomechanical factors and the Kinanthropometry characteristics of judo athletes. Inclusively, some investigations showed advantage in the biomechanical variables evaluated in judo techniques ${ }^{3}$, however, in biomechanics there are different levels of assessment that could be considered in judo ${ }^{8}$.

The first point is a group of basic assessment; muscle utilization of short-stretching cycle, limitation of muscle groups involved in performance and control of degrees of freedom involved in the chain of movement. Muscle utilization of the short-stretching cycle: During the start of any movement it is common to see joint variations in the opposite direction to the movement, generating an eccentric tension, these variations originate with the purpose of obtaining a contribution from the elastic components (fascia, tendons, sarcolemma and titin) of muscle tissue, which provides this contribution without any energy cost ${ }^{9}$. The mechanical characteristics that these structures have provide this energy accumulation, but this material also presents variations as a result of the holding time in the eccentric variation, temperature, level of flexibility and coordination. In judo, it is very important how an assessment is frequently used by trainers with squat jump and countermovement jump ${ }^{10}$ and the relation with Kinanthropometry characteristics, actuality assessment of shortening-stretching cycle is with force platform in variables; jump height, mean power, peak power, maximum force, and peak velocity, but the main problem is that the best variable in explosive force is rating of force development ${ }^{11}$ and the difference between squat jump and countermovement jump with this variable.

Limitation of muscle groups involved in performance (minimize energy expended): The optimal performance of a movement is based on the economy of effort, which includes limiting excessive movements and muscle groups for the motor task. These movements contribute to a decrease in energy used in muscle work and, therefore, the application of the concept of muscular efficiency, mainly determining differences in the control strategy in the muscles ${ }^{12}$. To assess the limitation of involved muscle groups, the electromyography of surface (EMGs) is used, in assessment of judo with EMGs in lower extremities in different throwing techniques where elite judokas revealed higher EMG activity of agonist muscles during throws but lower co-activation levels in different with sub elite judokas ${ }^{8}$. In the other hand, the judo-specific resistance training also has assessment with EMGs, where it shows that major EMG activities are: deltoid muscle, erector spinae muscle, trapezius muscle, but the main problem in this point is the form in which the different articles normalize the data of EMG, so the normalization to an maximal voluntary contraction (MVC) that is matched to the task in terms of joint angle/muscle length, contraction type, and/or joint angular velocity is the best form of normalizing the EMG signal when the movements evaluated are not maximal and it is necessary to search other mechanics of normalizing the signal EMG validation ${ }^{13}$.

Control of degrees of freedom involved in the chain of movement: The realization of a movement begins with the coordination of larger segments towards smaller and distal structures ${ }^{14}$. This chain of movement can be gen- 
erated in a more complex manner as more planes and axes of movement are added. The control of the force that is generated to carry out this movement must be adequate in both directions to achieve the motor task. In sports, the flexibility is a very complex assessment since tests are not valid and do not have global normative values. In the few validated global tests there is the sit and reach test, which is a field test used to measure hamstring and lower back flexibility of the population, but also widely used in athletes and to show normative values in sport ${ }^{15}$, being part of British Judo Tests. In judo is necessary to add major test that evaluates the flexibility in judokas.

\section{FINAL COMMENTS}

To this end, research from a broad range of performance analysis is likely to advance the understanding of this combat sport. If practitioners are to intervene effectively and enhance these skills, then a better understanding of how performance analysis associated with Kinanthropometry aspects is necessary. Further, this point of view has demonstrated that among judo players, the best achievers can be discriminated from analysis associated with biomechanical characteristics and the technical-tactical actions on the basis of their Kinanthropometry characteristics. There are limitations regarding the use of EMG that must be considered before performing this measurement. It should be noted, however, that the rating of force development is the most important biomechanical variable. Finally, there is a lack of studies concerning this subject, it is recommended that further research examines the use of novel technology as a means to differentiate between performance levels of athlete's Kinanthropometry factors, and give specific consideration to develop a specific testing and training protocol for judo players.

\section{COMPLIANCE WITH ETHICAL STANDARDS}

\section{Funding}

This research did not receive any specific grant from funding agencies in the public, commercial, or not-for-profit sectors. This study was funded by the authors

\section{Ethical approval}

This research is in accordance with the standards set by the Declaration of Helsinki

\section{Conflict of interest statement}

The authors have no conflict of interests to declare.

\section{Author Contributions}

Conceived and designed the experiments: CJB; EAM; BM. Performed the experiments: CJB; EAM; BM. Analyzed the data: CJB; EAM; BM. Contributed reagents/materials/analysis tools: CJB; EAM; BM. Wrote the paper: CJB; EAM; BM. 


\section{REFERENCES}

1. Dal Bello F, Aedo-Muñoz E, Brito CJ, Miarka B. Performance analysis and probabilities by gender in judo: combat phases, techniques and biomechanical levers. Facta Univ Phys Educ Sports 2019;17(1):135-48.

2. Miarka B, Brito CJ, Amtmann J, Cordova C, Bello FD, Camey S. Suggestions for Judo Training with Pacing Strategy and Decision Making by Judo Championship Phases. J Hum Kinet 2018;64:219-32.

3. Ishii T, Ae M, Suzuki Y, Kobayashi Y. Kinematic comparison of the seoi-nage judo technique between elite and college athletes. Sports Biomech 2018;17(2):238-50.

4. Miarka B, Sterkowicz-Przybycien K, Fukuda DH. Evaluation of Sex-Specific Movement Patterns in Judo Using Probabilistic Neural Networks. Motor Control 2017;21(4):390-412.

5. López Díaz-de-Durana A, Bello Fd, Brito CJ, Miarka B. High level performance in world judo circuit: Notational analyzes of combat phase by weight categories. J Human Sport Exerc 2018;13(PROC2):S329-S38.

6. Sterkowicz-Przybycien K, Miarka B, Fukuda DH. Sex and Weight Category Differences in Time-Motion Analysis of Elite Judo Athletes: Implications for Assessment and Training. J Strength Cond Res 2017;31(3):817-25.

7. Brito CJ, Miarka B, Durana ALD, Fukuda DH. Home Advantage in Judo: Analysis by the Combat Phase, Penalties and the Type of Attack. J Hum Kinet 2017;57:213-20.

8. Zaggelidis G, Lazaridis S. Muscle activation profiles of lower extremities in different throwing techniques and in jumping performance in elite and novice greek judo athletes. J Hum Kinet 2013;37(1):63-70.

9. Pedraza Mejías C, Martínez Cañadas J. Physiological response of the muscular and tendinous conjunctive tissue after application of physical agents. Fisioterapia 2008;30(6):279-85.

10. Monteiro LF, Massuça LM, García JG, Carratala V, Proença J. Plyometric muscular action tests in judo-and non-judo athletes. Isokinet Exerc Sci 2011;19(4):287-93.

11. McLellan CP, Lovell DI, Gass GC. The role of rate of force development on vertical jump performance. J Strength Cond Res 2011;25(2):379-85.

12. Trevino MA, Herda TJ. The effects of training status and muscle action on muscle activation of the vastus lateralis. Acta Bioeng Biomech 2015;17(4):107-14.

13. Besomi M, Hodges PW, Clancy EA, Van Dieën J, Hug F, Lowery M, et al. Consensus for experimental design in electromyography (CEDE) project: Amplitude normalization matrix. J Electromyogr Kinesiol 2020:102438.

14. Sterkowicz S, Lech G, Sterkowicz-Przybycień K, Chwała W, Ambroży T, Pałka T. Relationship of maximal isometric torque produced in flexors and extensors rate to technique by judo athletes. Acta Bioeng Biomech 2018;20(2):65-71.

15. Aedo-Muñoz E, Araya-Ibacache M, Miarka B, Moya-Jofre C, Cancino-López J, Mozer RL, et al. Effect of sex differences in sports groups on hamstring flexibility based on the sitreach test: new parameters for Chilean athletes. J Phys Educ Sport 2019;19(4):2374-8.

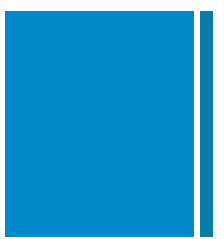

\section{Corresponding author}

Ciro José Brito.

Department of Physical Education.

Federal University of Juiz de Fora.

José Lourenço Kelmer st. - Martelos, Juiz de Fora - MG - Brazil

Postal Code: 36036-330

E-mail: cirojbrito@gmail.com 